\title{
Assessing site response through ambient noise measurements in a seismic prone area
}

\begin{abstract}
Ambient noise measurements are carried out at 70 sites in different parts of Shillong City, NER, and India. The minimum duration of noise recording is about 60 minutes. We estimate the $\mathrm{H} / \mathrm{V}$ ratio from these recordings. The fundamental resonant frequency for Shillong City emerges out to be in the range of 3 to $8 \mathrm{~Hz}$. Variation in the resonant frequencies suggests that heterogeneity is prominent in the soil layers of this region. Simultaneously, a non-linear earthquake site response analysis is also attempted using available geotechnical data. A good correlation is observed between site response analysis and HVSR results constrained by wide variation of resonant frequency at short distances in the $\mathrm{H} / \mathrm{V}$ ratio which indicate a lateral heterogeneity prevailing in the soil layers of the region.
\end{abstract}

Keywords: ambient noise, $\mathrm{H} / \mathrm{V}$, site response, geotechnical data
Volume 3 Issue 2 - 2019

\author{
Rajib Biswas,' Saurabh Baruah² \\ 'Department of Physics, Tezpur University, Tezpur 784028, India \\ ${ }^{2}$ Geoscience Division, CSIR North East Institute of Science and \\ Technology, Jorhat 785006, India
}

Correspondence: Rajib Biswas, Department of Physics, Tezpur University,Tezpur 784028,Assam, India, Email rajib@tzu.ernet.in

Received: November 26, 2017 | Published: March 19, 2019

\section{Introduction}

Northeast Region (NER) of India, bounded by latitude $\left(28-30{ }^{\circ} \mathrm{N}\right)$ and Longitude $\left(89-98^{\circ} \mathrm{E}\right)$, is seismically one of the most active zones in the world where sixteen large $(\mathrm{M}>7.0)$ and two great earthquakes of June 12, 1897(M 8.5 $)^{1}$ and August $15,1950(\mathrm{M}=8.7)^{2}$ occurred during the last hundred years. These two great earthquakes have caused extensive destruction killing a total of 3,042 lives and a total loss of \$ 30 million. ${ }^{3}$ Consequently, the NER, India lays in the seismic zone V of India. ${ }^{4}$ The zone $\mathrm{V}$ is the maximum rating zone of India. Shillong Plateau is a part of the Indian Shield, which is separated out from the peninsular shield and moved to the east by about $300 \mathrm{Km}$ along the Dauki Fault. ${ }^{5}$ The gigantic E-W trending Dauki Fault separates the plateau from the Himalaya to the North. The E-W segment of the river at the northern boundary of the Plateau is named Brahmaputra fault. ${ }^{6}$ The Shillong City, i.e., the study area is situated in Shillong Plateau. The complex geotectonic setup of Shillong City needs better understanding of site-amplification characteristics. The city in particular has not been covered by any proper estimation of fundamental frequency. It has been observed that the damage associated with the occurrence of earth tremors is not only due to magnitude of the earthquake of earth tremors and its epicentral distance, but also due to local site effects which are essentially frequency dependent caused by the topography and geology of the site. ${ }^{7}$

The interaction of the local geological conditions to the incoming seismic energy is known as the local site response. The geological structure behaves as a selective filter shaping the spectrum of energy shaking the ground. ${ }^{8}$ Moreover, the damage pattern in urban area during an earthquake depends on the characteristics of the extent and of the interaction between the site response and vulnerability of the exposed structures. ${ }^{9,10}$ For seismic hazard assessment, the site effect is typically represented by resonance frequency and the associated ground motion amplification. Several methods exist such as array data analysis, horizontal to vertical ratio HVNSR, site to reference spectral ratio with a view to estimate such parameters. Out of these, use of ambient vibration records ${ }^{11-20}$ for determination of fundamental resonant frequency has recently gained world-wide acceptance. It is well known that soil deposits amplify ground motion. The amount of amplification depends on several factors including layer thickness, degree of compaction and age. ${ }^{18,19}$ Amplification of earthquake motion by sediments is an important parameter in determining seismic hazard. It is also found that the variation of ground motion shaking can be very severe at very short distances provided that there is a complex sub-surface structure. ${ }^{21,22}$ Note worthy is the fact that the younger sediments amplify more compared to competent soil or bedrock. It is also a matter of concern that most of the urban settlements have occurred along river valleys over such young and surface deposits. ${ }^{23}$ This is because at site, having soft soil or topographic and basement undulations, seismic energy gets trapped, leading to amplification of vibration of manmade structures. ${ }^{17-20}$

One of the many reasons for choosing ambient noise as widely accepted by several authors is that it allows the quick \& reliable estimate of site characteristics of any type of area. ${ }^{9-18}$ Apart from being a cost effective measure, it reduces time compared to estimating site characteristics from earthquake which has always been a time consuming as well as expensive process so far as the maintenance of equipment \& man power is concerned. There are many instances of successful utilization of this $\mathrm{H} / \mathrm{V}$ ratio estimate towards studying fundamental frequency from ambient vibrations in urban environments. ${ }^{24-28}$ The proximity of fundamental frequency of a site to the existing man-made structures causes damage of the later owing to resonance effects. So far the estimation of PGA is concerned, some author show that PGA in near-field zone is not amplified on soft ground and is even slightly decreased. For example, during the San Fernando earthquake for epicentral distances $>50 \mathrm{~km}$ PGA is larger on soil, while for $<50 \mathrm{~km}$ it is smaller. ${ }^{29}$ Simultaneously it is observed that the most important factor for relation between horizontal and vertical components is the vibration level for strong ground motion records. ${ }^{30}$ Therefore, investigation of each site condition is an important step towards earthquake hazard mitigation. One of the most striking features of Northeastern India is that most of its cities and densely populated settlements are located in valley, sedimentary basins or hills etc. In this study, we try to shed light upon the site characteristics of Shillong City in terms of resonant frequency, site amplification etc with $\mathrm{H} / \mathrm{V}$ ratio methodology. ${ }^{31}$ Additionally, an attempt has been made to simulate ground motion in this area w.r.t felt earthquakes with the help of nonlinear earthquake site response analysis.

\section{Description of the site}

Shillong is considered as one of the heritage cities in NER, India. It is the capital of Meghalaya, situated in almost elliptically shaped Shillong Plateau (SP). It covers an area of 6430 square kilo meter. The population of Shillong City is around 2, 70,000. Increase in its 
population resulted in rapid urbanization. As a consequence of this growing urbanization, man-made structures especially high rise buildings are being built $\&$ under construction as well in the central part of the township.

\section{General settings}

\section{Geology of the site}

Shillong has an altitude of 1496 meters above sea level. It is bounded by the Umiam Gorge to the North, Diengiel Hills in the Northwest and Assam valley to the north-east. The SP with an Achaean gneissic basement and late Cretaceous-tertiary sediments along its southern margin is bounded by the Brahmaputra graben in the north and by Dauki fault in the south. ${ }^{32}$ Existence of several lineaments in and around city having major trends along NE-SW, N-S and $\mathrm{E}-\mathrm{W}$ directions $\mathrm{s}^{33}$ makes the city more vulnerable so far earthquake hazard is concerned. Shillong forms the type area of Shillong series of parametamorphites, which includes mostly quartzites and sandstones followed by schist, phyllites, slates etc. ${ }^{34,35}$ The base of Shillong series is marked by a conglomerate bed containing cobbles and boulders of earlier rocks, i.e., Archaean crystalline, which formed the basement over which the Shillong series of rocks were originally laid down as sedimentary deposits in Precambrian times, probably in shallow marine conditions. The rocks that were intruded by epidiorite rocks are known as "Khasi Greenstone" as depicted in the Geological map of Shillong in Figure 1. The Khasi Greenstone ${ }^{36,37}$ is a group of basic intrusives in the form of linear to curvilinear occurring as concordant and discordant bodies within the Shillong group of Rocks and suffered metamorphism. ${ }^{38}$ These kinds of rocks are widely weathered and the degree of weathering is found to be more in topographic depressions than in other areas. The metabasic rocks are more prone to weathering than the quartzite rocks. In low lying areas, valley fill sediments are also prominent.

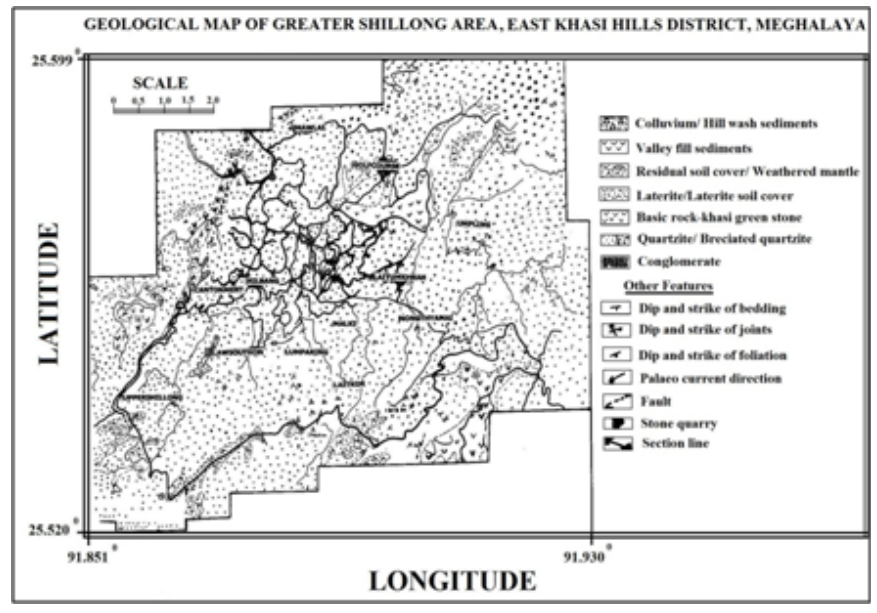

Figure I Geological map of Shillong City.

\section{Seismotectonics of shillong city}

The study area, Shillong City is a component of Shillong Plateau which is regarded as one of the most seismically active region in NER, India. The Plateau is separated out from the peninsular shield and moved to the east by about $300 \mathrm{~km}$ along the Dauki fault. ${ }^{5}$ It is surrounded by many small \& large faults \& lineaments. Towards the western part of Shillong, there exists the active Barapani Shear Zone. It is one of the major thrust faults prevailing in this region. The complex geodynamics of Shillong Plateau resulted in the Great
Assam earthquake of 1897. As reported by Bilham et al., ${ }^{39}$ this $\left(M_{S}=8.7\right)$ earthquake caused severe damage to the settlements of this area (Shillong city), causing causalities in a large dimension. It may be mentioned about a significant earthquake of June 1, 1969 with a magnitude of 5.0 having an Epicentral distance of $20 \mathrm{~km}$ from Shillong ${ }^{40}$ which was felt rigorously. According to Gupta, since 1970, there has been gradual decrease in P-wave velocity yielding a speculation that the region is experiencing a dilatancy stress precursory to a large earthquake. According to Khatri et al., ${ }^{41}$ the Shillong Massif shows a pertinent seismic activity with an average of 10-15 small magnitude earthquakes per day. Over the past hundred years, there were instrumental records of 20 large earthquakes. With the advent of seismic networks set up by NEIST Network, IMD, there has been a tremendous improvement in the recording of micro tremors. The moderate magnitude seismicity in the Shillong area is somewhat confined to Barapani Shear zone. During the past recent months, there has been a contemporary rise in the no. of felt tremors whose epicenters lie within the vicinity of Shillong City. In the context of this ongoing pattern of seismicity, the current study will be an initiative towards microzoning of this region. The major tectonic features surrounding Shillong is displayed in Figure 2.

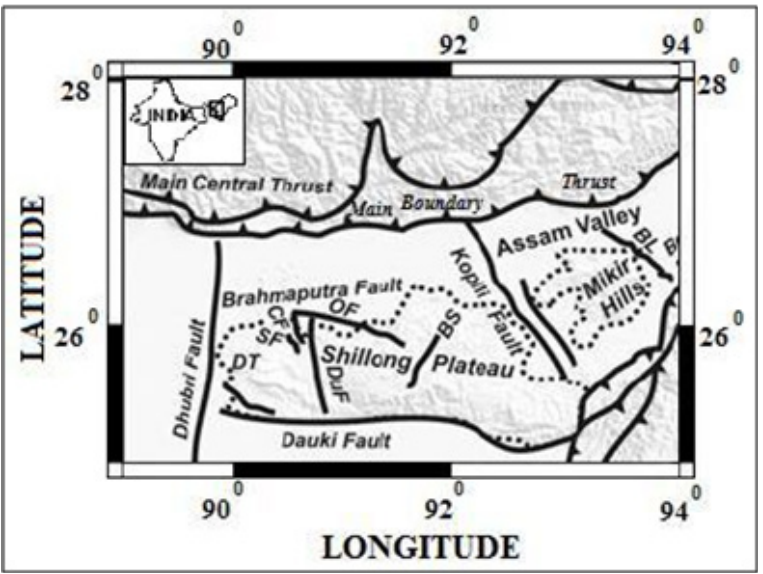

Figure 2 Map showing major tectonic features of Shillong plateau after Baruah and Hazarika (2008). The inset map shows the study region. BS-Barapani Shear Zone; SF- Samin Fault; DT- Dapsi Thrust; Du F- Dudhnoi Fault; OF- Oldham Fault; CF-Chedrang Fault; BL- Bomdila Lineament.

\section{Experimental design}

\section{Field survey and data acquisition}

The ambient noise survey was carried out in Shillong City covering 70 sites in total. Since, Shillong is an urban populous city; hence there are certain constraints regarding noise recording in urban environments. To ensure reliable noise recording, the survey was performed twice where there was a possibility of artificial noise sources such as moving cars, pedestrians. Moreover, quiet environment \& good weather condition had been our prime requisite during data acquisition process. During data acquisition, the sensors were installed at the recording sites strictly following the Guidelines by SESAME, 2004. A three component short period S-13 seismometer from M/S Teledyne Geotech, USA having natural period of 1s was used. The duration of data recording is more than 1 hour. We utilized 24 bit Reftek 72-0A digitizer. The recording was carried out at 100 samples per second and recording time was maintained by Reftek GPS clock. The GPS locations of the ambient noise sites are shown Figure 3. 


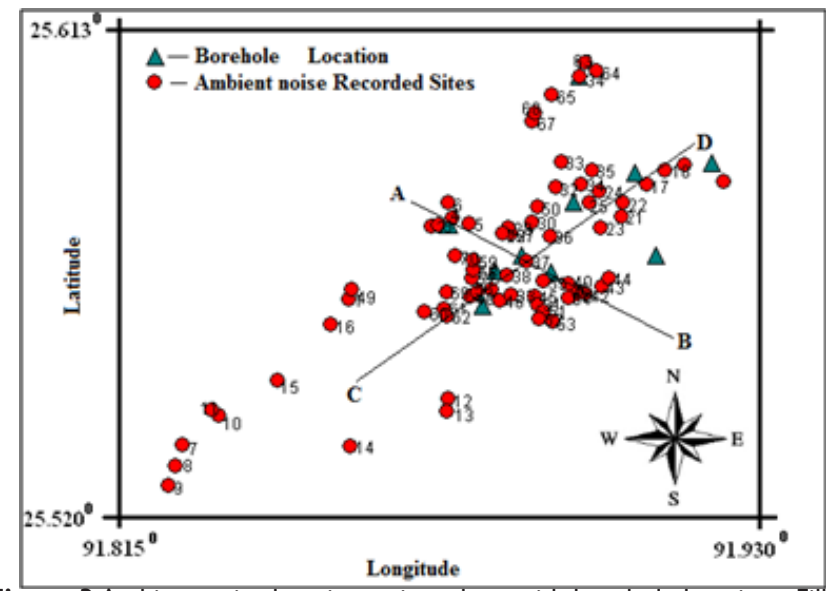

Figure 3 Ambient noise location points along with borehole locations. Filled circles represent the location of the sites where ambient noise recordings, represented by no's as well are made. Filled triangles refer to the location of the boreholes. $A B$ and $C D$ are the observed profiles.

\section{Data processing}

Data from each site have been processed using LGIT Software i, e; SESARRAY package. Since the same type of sensor has been used for all the three components, no instrumental correction has been applied. Below are listed the processing parameters.

I. Determination of stable windows is made in the 30-40s range, using an antitrigger with 1-s STA and a 30s-LTA. The threshold values of STA/LTA ratio are 0.25 and 2.50 as minimum and maximum respectively.

II. For each window, a $5 \%$ cosine taper is applied on sides of the window of the signal of vertical (v), North-South and East-West components.

III. For each window, an FFT is applied to the three components signal to obtain the three spectral amplitudes, to which a smoothing factor by Konno et al., ${ }^{42}$ is applied with a bandwidth of 40 and followed by an arithmetical average of the horizontal components.

IV. Subsequently, spectral ratios (NS/V, EW/V), and arithmetically averaged (NS, EW)/V are computed.

\section{H/V Curves and peaks reliability}

In general, the spectral amplitudes and spectral ratios are obtained in accordance with the general conditions for $\mathrm{H} / \mathrm{V}$ curve reliability. In order to check the reliability of $\mathrm{H} / \mathrm{V}$ peak estimated under this study from which the fundamental frequency of resonance is computed, we ensure ourselves that it fulfils following criteria of the SESAME Guidelines (2004) which are followed by many researchers throughout the world.

I. H/V peak amplitude should be equal or greater than 2 .

II. Between $\mathrm{f}$ and $4 * \mathrm{f}$ ( $\mathrm{f}$ is the fundamental frequency), there must be a frequency which amplitude is less than half of the peak frequency peak.

III. The frequency standard deviation $\left(\sigma_{\mathrm{f}}\right)$ for each peak $\left(\mathrm{f}_{0}, \mathrm{f}_{1} \ldots\right)$ should be less than a frequency dependant threshold, described in detail in SESAME,2004;
IV. The amplitude standard deviation $\left(\sigma_{\mathrm{A}}\left(\mathrm{f}_{0}\right)\right)$ of a $\mathrm{H} / \mathrm{V}$ peak $\left(\mathrm{A}_{0}\right.$, $\left.A_{1}, \ldots ..\right)$ should be less than threshold (frequency dependant) fixed in SESAME, 2004;

V. The peak should appear at the same frequency (within $\pm 5 \%$ ) on the $\mathrm{H} / \mathrm{V}$ curves corresponding to the mean plus and minus one standard deviation.

Simultaneously, to ensure whether an $\mathrm{H} / \mathrm{V}$ peak is of natural or anthropic origin, each $\mathrm{H} / \mathrm{V}$ peak is tested by Randomdec method. ${ }^{43,44}$ As observed, the origin of the $\mathrm{H} / \mathrm{V}$ peak is ascertained to be of anthropic origin if the critical damping is found below $5 \%$; otherwise it is considered to be generated by natural origin wherein we get a critical damping above 5\%. An example is depicted in Figure 4. The frequency, pertaining to the low damping, as affirmed by the Randomdec technique to be of industrial origin is not considered for further processing and analysis. As an example, the origin of the $\mathrm{H} / \mathrm{V}$ estimate w.r.t site no 42 is tested through damping results. It is observed in Figure 4 that the damping is reasonably higher than the threshold of 5\% for all the three components, thus affirming the origin of this peak to be of natural origin. The corresponding $\mathrm{H} / \mathrm{V}$ estimate for this site is given in Figure 5.

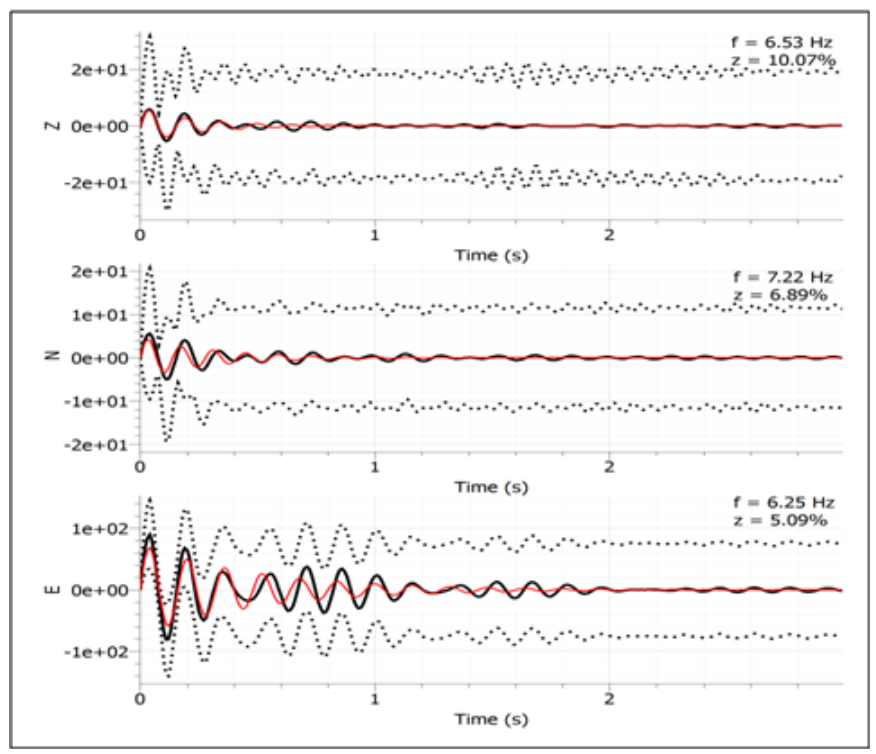

Figure 4 Damping results from Randomdec Method to check the origin of the $H / V$ estimate of peak frequency for a particular site.

\section{Results}

Following the guidelines of SESAME and after Randomdec Method, the $\mathrm{H} / \mathrm{V}$ ratios are evaluated for the sites where ambient noise recordings were made. Particularly, two types of frequencies are observed to exist from the $\mathrm{H} / \mathrm{V}$ ratio estimates. The first category of frequency is ranged between 1 to $2 \mathrm{~Hz}$ while the other range of frequency is found above $2 \mathrm{~Hz}$ as displayed in Figure 5. The low frequency peaks as illustrated in Figure 6 might be related to the existence of low velocity zones. Similarly, the resonant frequencies which are placed in higher category of frequency might be caused by the presence of hard soil strata. These results are more detailed in our next observation where we aim at searching for correlation with local geology. Reasonably, sharp peaks are observed in the Site $30,42,13 \& 64$. These sites are representative of the $\mathrm{H} / \mathrm{V}$ ratio estimates performed for the majority of the sites. The sites portrayed 
in Figure 6 yield some low frequency peaks which are not sharply defined. Several theoretical 1D investigations ${ }^{45-47}$ shows that $\mathrm{H} / \mathrm{V}$ ratio exhibits fundamental frequencies with sharply defined peaks when there exists a sharp impedance contrast between the surface layer \& the underlying stiffer formations. Comparison of Figure 5 \& Figure 6 reveal the fact that the low frequency peaks which is also not so sharp might be caused by surface layer having moderate impedance contrast with the underlying formations. The overall fundamental frequency from $\mathrm{H} / \mathrm{V}$ ratio estimates of all the 70 sites of Shillong is elaborated in the form of contour in Figure 7. It is observed in the contour that certain regions which are encompassed by higher frequencies from 5 to $7 \mathrm{~Hz}$ are covered by compact strata of rocks such as greenstones, quartzite as evidenced in the Geological map of Shillong (Figure 1). Simultaneously, certain sites in the heart of the Shillong city exhibit lower fundamental frequency in the range of 1 to $2 \mathrm{~Hz}$. When compared with geological map, it reveals the fact these sites which exhibit lower fundamental frequency are marked by the presence of weathered soil cover which are considered as one of low velocity zone corroborating the findings of low fundamental frequency.

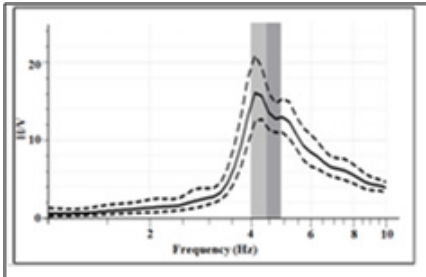

(a) SiteNo. 30

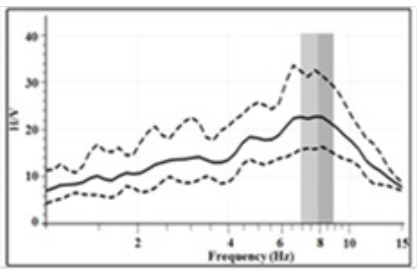

(c) Site No.13

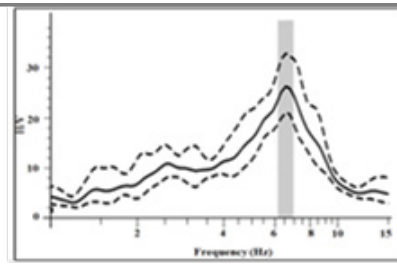

(b) SiteNo. 42

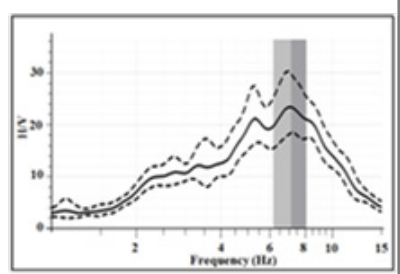

(d) SiteNo. 64
Figure $5 \mathrm{Higher}$ fundamental frequencies from $\mathrm{H} / \mathrm{V}$ ratio. The grey vertical line represents the peak of the $\mathrm{H} / \mathrm{V}$ ratio corresponding to the resonant frequency, The dashed line indicates the standard deviation whereas the average $H / V$ ratio is indicated by the solid line.

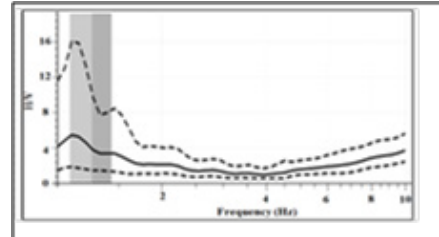

(a) 5 int $: 0.27$

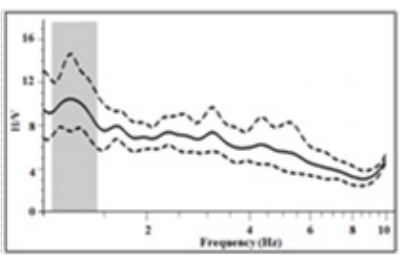

(c) Site No. 50

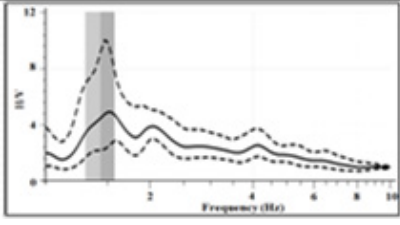

(b) Sitt No. 54

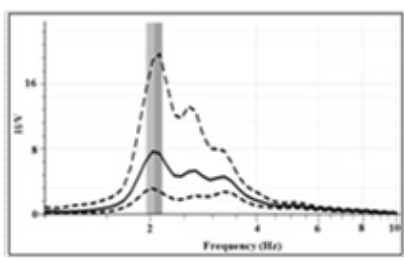

(d) Site No.21
Figure $6 \mathrm{H} / \mathrm{V}$ ratio results encompassed by low frequency peaks.

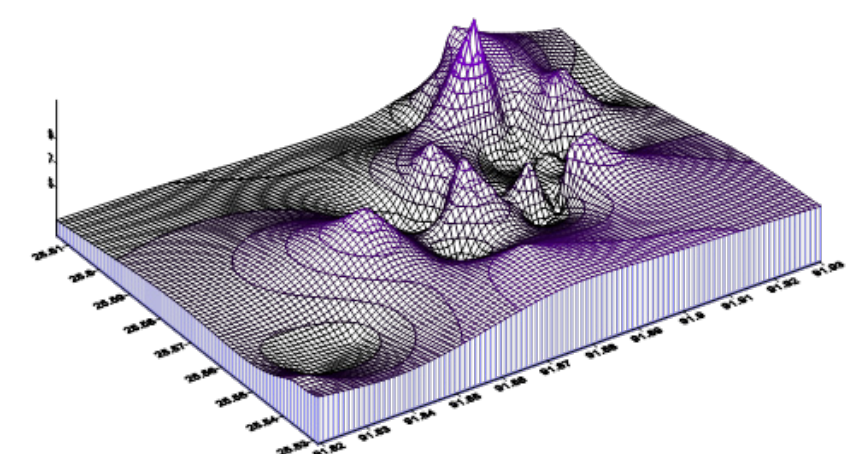

Figure 7 Contour plots showing the distribution of fundamental frequencies computed from $\mathrm{H} / \mathrm{V}$ ratio for the entire Shillong Area.

\section{H/V profiling-relation between amplitude of the frequency w.r.t sites}

$\mathrm{H} / \mathrm{V}$ profiling is an important feature to visualize how the $\mathrm{H} / \mathrm{V}$ ratio estimates vary over a certain section. This allows one to have a general inspection regarding the variation of resonance frequency in accordance with distance of the sites from each other. Additionally, the corresponding amplifications levels at the site can also be studied with this. In this study, two profiles are considered in order to observe the variation w.r.t resonance frequency or distance. This has been done keeping in view of the close proximity of the borehole logs with that of the ambient noise recording sites. $\mathrm{AB}$ and $\mathrm{CD}$ are the two profiles wherein the variation of $\mathrm{H} / \mathrm{V}$ amplitudes is observed, as shown in Figure 3. Figure 8 illustrates the $\mathrm{H} / \mathrm{V}$ profiling corresponding to the profile $\mathrm{AB}$. The profile is characterized by comparable variation in frequencies, covering very low to very high frequencies. The sites numbered 4, 6 and 67 exhibit higher frequencies in the range of 5.5 to $8 \mathrm{~Hz}$. Lower frequencies less than $2 \mathrm{~Hz}$ are observed in two sites numbered 2 and 50 . Another aspect can also be contemplated in this figure. The sites showing higher range of frequencies are also masked by higher amplitudes. As for the CD profile, the variations are observed in Figure 9. It is quite evident in the figure that except two sites, majority of the sites correspond to higher frequencies. It is found to be in the range of 4 to $6 \mathrm{~Hz}$. The two sites numbered 22 and 51 refer to low frequency sites. So far the amplitude variation corresponding to the peak frequencies are concerned, similar trend is visible as observed in $\mathrm{AB}$ profile. Though the level of amplitudes is quite high compared to the former, relatively higher frequencies encompasses the higher amplitudes. All these observations are substantiated in the next section when they are correlated with the existing litholog available in the immediate neighborhood of the recording sites.

\section{Correlation with Geomorphology}

The litholog information of Shillong city is scanty. However, we could obtain litholog information of 14 sites exclusively in Shillong City where borehole loggings were carried out. In order to observe any correlation between fundamental frequency and geology, two specific profiles are drawn which are in conformity with the location of the boreholes \& the neighboring ambient noise recording sites. These are profile $\mathrm{AB}$ and profile $\mathrm{CD}$ as illustrated in Figure 3. Profile $\mathrm{AB}$ aligns with the three borehole sites available in the region. Similarly, profile $\mathrm{CD}$ which trends in NE direction covers six borehole sites. With the objective of correlating the existence of fundamental frequencies with existing lithology, many researchers resorted to reconstructing the 
geology with the available geophysical information. Mention may be made about the works of Cara. ${ }^{9}$ On the basis of borehole data, we made an attempt to reconstruct geological cross-sections along the two observed profiles as displayed in Figure 8 \& Figure 9, following Cara et al. ${ }^{9}$ The layerings in the two reconstructed geological cross sections are made with the litholog information available. Each reconstructed geological cross-section is well represented with the site-amplification behavior. The resonance frequencies estimated from $\mathrm{H} / \mathrm{V}$ ratio in different sites are correlated with reconstructed geological crosssection. As shown in Figure 8, we divide the resonance frequencies into three different ranges. The first range is from 1 to $3.5 \mathrm{~Hz}$; next 3.5 to $5.5 \mathrm{~Hz} \&$ the highest one range between 5.5 to $7.5 \mathrm{~Hz}$ or above. Similarly pertaining to profile $\mathrm{AB}$ oriented along NW-SE, there is a transition of resonance frequency from higher in northwest part to lower frequency towards southeast region. In the higher frequency portion, it comes within an average of $5 \mathrm{~Hz}$. Thus, it can be attributed that the southeast part is dominated by lower resonance frequency in comparison to northwest part.

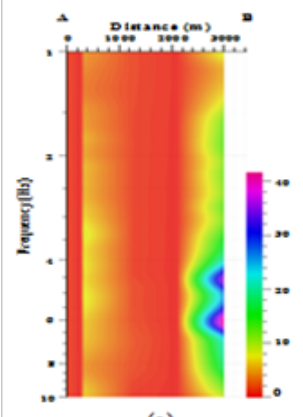

(a)

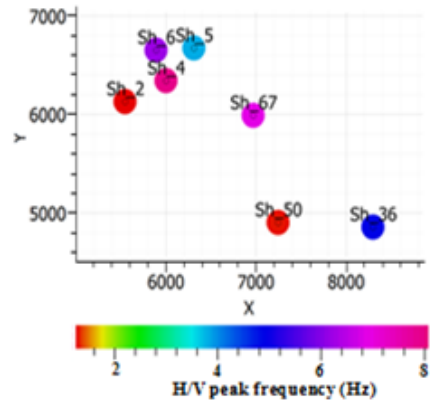

(b)
Figure 8 (A) Variation of fundamental frequencies along $A B$ profile. Along the vertical axis, fundamental frequency is plotted and distance is provided along horizontal axis. The color scale appearing at the right indicates the variation of amplitudes corresponding to the computed fundamental frequencies. (B) Plot of ambient noise sites falling in the profile $A B$. Along $X$ and $Y$ axis; distances in meters among the sites are shown. The color scale implies the corresponding site-specific $\mathrm{H} / \mathrm{V}$ peak frequencies.

The existence of higher frequencies may be attributed to the presence of hard rock strata along the NW part of the profile. This observation holds well as inferred from the site specific ambient noise analysis except some non-conformity in site no. 28 \& 29. Notably, site no. 4 \& 5 showed higher resonant frequencies, consistent with the presence of more compact thicker rock strata (sand rock; as shown in the reconstructed cross-section). Towards the SE edge of the profile, mainly low frequency dominates the region. An inspection at the reconstructed portion leads to the fact that there exists a comparatively lower density clay stratum. The little variation may be attributed to the degree of compactness of the strata as also inferred in Cara et al., ${ }^{9}$ However, a wide variability in resonance frequencies starting from SW part to N-S region is contemplated in profile $\mathrm{CD}$, as illustrated in Figure 10. Along the profile, site no's 69, 56 \& 39 show a gradual transition to higher fundamental frequencies from the lower resonant frequency characterizing the sites $60,61 \& 62$. This might be attributed to the presence of low S-wave velocity zones beneath. Perhaps, thickening of weathering layer can be another contributing factor towards this abrupt transition. Additionally, it is observed that sites 37, 32, $34 \& 21$ exhibits lower fundamental frequencies. Towards SE direction along the profile there is a sudden transition to higher value of fundamental frequency observed as $6.5 \mathrm{~Hz}$ at site no 20. This sudden transition may be attributed to the local geology of the site which is the juncture of sand granite and sand rock as depicted in the reconstructed cross section see Figure 11.

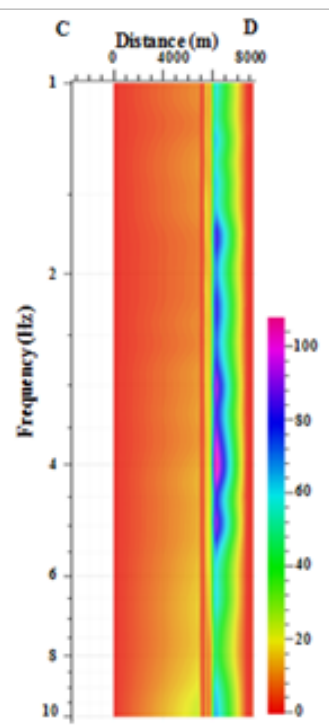

(a)

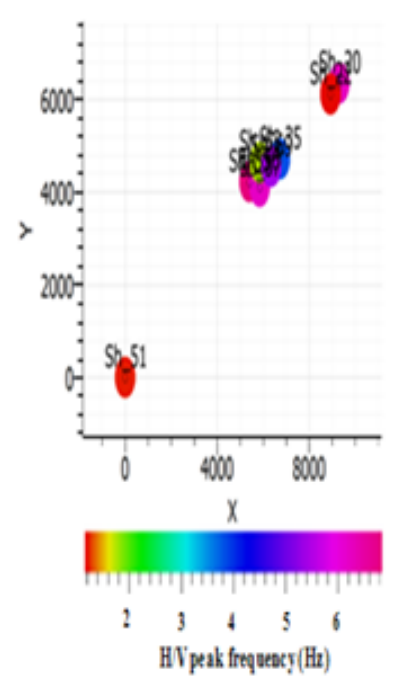

(b)
Figure 9 Variation of fundamental frequencies along CD profile. Along the vertical axis, fundamental frequency is plotted and distance is provided along horizontal axis. The colour scale appearing at the right indicates the variation of amplitudes corresponding to the computed fundamental frequencies. (b) Plot of ambient noise sites falling in the profile $C D$. Along $X$ and $Y$ axis; distances in meters among the sites are shown. The colour scale implies the corresponding site-specific $\mathrm{H} / \mathrm{V}$ peak frequencies.

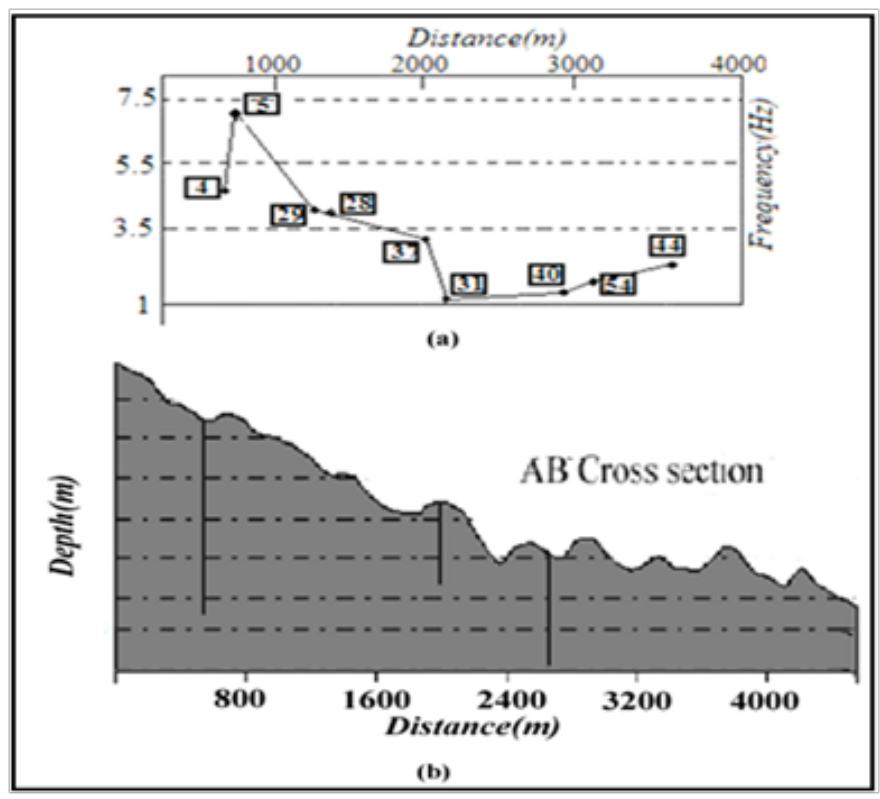

Figure 10 Variation of fundamental frequencies along $A B$ profile. The figures in the boxes indicate the ambient noise sites alongside of $A B$ profile. The bold vertical lines indicate the location of the boreholes (b) Depiction of lithosection along $A B$ profile with corresponding topographical variation. Here, depth is projected vertically downward with an equal interval of $50 \mathrm{~m}$. 


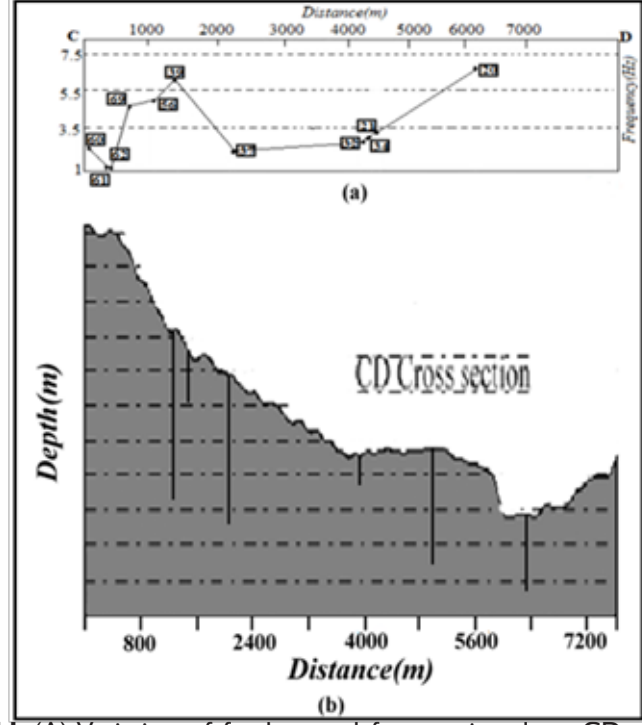

Figure II (A) Variation of fundamental frequencies along CD profile. The figures in the boxes indicate the ambient noise sites alongside of $C D$ profile. The bold vertical lines indicate the location of the boreholes (B) Depiction of litho-section along $C D$ profile with corresponding topographical variation. Here, depth is projected vertically downward with an equal interval of $50 \mathrm{~m}$.

\section{Non-linear site response analysis}

In order to validate the $\mathrm{H} / \mathrm{V}$ estimates, we perform a numerical analysis to simulate one felt earthquake recorded by local Strong motion Networks. The hypocentral parameters are given in. The reason for choosing this earthquake lies in the fact that it has the epicenter situated at a distance of less than $140 \mathrm{~km}$. This earthquake of magnitude 5.1 $\left(\mathrm{M}_{\mathrm{w}}\right)$ was felt at several places in the adjoining areas of Shillong City. With a view to simulate this earthquake, we adopted the technique of nonlinear earthquake site Response analysis (NERA) developed by JP Bardet et al., ${ }^{48}$ Required geotechnical parameters such as $\mathrm{N}$ values from Standard Penetration Tests are the essential input to this software. Utilizing the available input parameter, ground acceleration of the $19^{\text {th }}$ August, 2009 event could be simulated at ten Borehole sites. It has become a wide practice of using empirical relation that relates shear wave velocity with $\mathrm{N}$ values of Standard Penetration Test when there is a dearth of Geophysical parameters. In this study, the empirical relationship of Imai \& Tonochi, 1982; Ohta \& Goto, 1978 are used to compute shear wave velocity in order to define the soil profile see Figure 10 required for the numerical analysis. The empirically determined estimates of shear wave velocities are found to be consistent when compared with a recent study by Raghukanth et al., in Imphal City, NER, India. Though the site geology is different for Imphal and Shillong City, it implies that this procedure of empirical estimation is valid in this study region also. For example, in Figure 10, three soil profiles are displayed viz., Arbhutnot Road, Pynthorumlhrah and East-Pinewood Hotel. Here, the maximum shear wave velocities as found from the empirical relations come in the range of $450 \mathrm{~m} / \mathrm{s}$. Here, we intend to validate the resonance frequency estimated through non-linear earthquake site response analysis near the borehole sites with the resonance frequency obtained through $\mathrm{H} / \mathrm{V}$ ratio from ambient noise. Utilizing the shear wave velocity profile, the soil profiles are estimated at all the 10 sites.

Simultaneously, the spectral acceleration and fundamental frequencies are estimated through nonlinear earthquake response analysis. Spectral acceleration bears a significant role in the damage associated with strong motions. It is referred to as the acceleration experienced by the existing structures whereas peak ground acceleration is the acceleration experienced by a particle. Figure 10 exemplifies the estimated parameters for Umpling, one of the Borehole sites. The estimated values are shown in. The estimates indicate varying ground motion parameters pertinent to all the borehole sites. Simulation of the accelerograms allows estimation of fundamental frequencies which range between $5-12 \mathrm{~Hz}$. The fundamental frequencies derived from nonlinear response analysis are found to be consistent with the estimations obtained from $\mathrm{H} / \mathrm{V}$ technique in majority of the borehole sites as detailed in. In case of sites e.g. Basic Science, Sawlad \& Near 13A tank, the resonance frequencies are overestimated w.r.t $\mathrm{H} / \mathrm{V}$ ratio estimates. The conformity of the fundamental frequencies done from simulation of ground motion of the event with the H/V computations indicates the consistency in our approach towards estimating resonance frequencies. Higher spectral acceleration is observed in Pynthorumkhrah which may be attributed to the weathered soil cover, as evidenced from local geology. Validation of our results through simulation of ground motion of earthquake with the help of Non linear earthquake site response analysis affirms the notion that $\mathrm{H} / \mathrm{V}$ ratio can be utilized for a reliable estimation of fundamental resonance frequency.

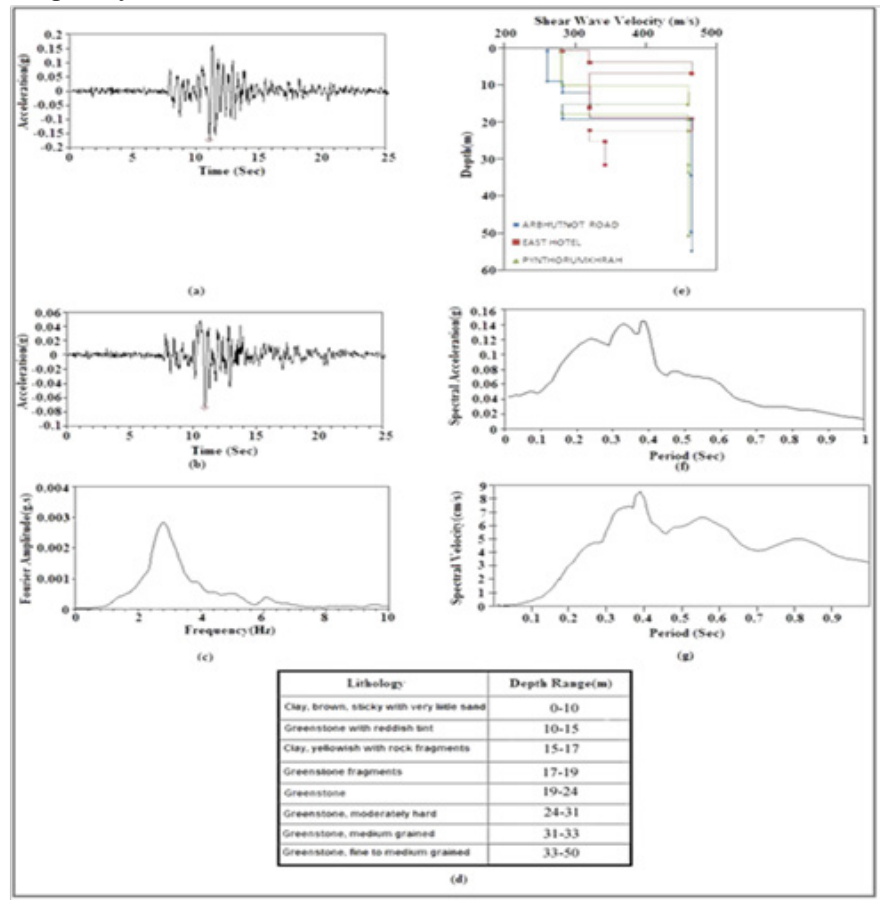

Figure 12 Estimated parameters from non-linear earthquake site response analysis. (A) Input acceleration time history of 19-08-09 event. (B) Simulated acceleration history. (C) Estimated fundamental frequency. (D) Borehole log data at one of the borehole site. (E) Shear wave-velocity profile of three borehole sites viz. Arbhutnot Road. East of Pinewood Hotel (abbreviated as East Hotel) \& Pynthorumkhrah. (F) Spectral acceleration. (G) Spectral Relative Velocity.

\section{Discussion}

In this work, an attempt is made to estimate site response through horizontal to vertical ratio from ambient noise analysis. Pertaining to this aim, ambient noise records are utilized which were accrued in seventy different sites in Shillong City. The collection of ambient noise records at these sites were performed keeping in view the proper soil-sensor coupling and other data related parameters. Afterwards, a 
distinctive analysis towards selection of suitable data is done, followed by preprocessing based on the SESAME ${ }^{49}$ guidelines. Site-specific resonant frequencies for all the seventy sites are computed through $\mathrm{H} / \mathrm{V}$ ratio. Prior to this, the $\mathrm{H} / \mathrm{V}$ curves are subjected to different reliability tests so as to decipher the reliable fundamental frequencies. Moreover, identification of the nature of origin of peak resonant frequencies is accomplished in order to achieve the best one pertinent to the site. All these are performed with the aim of inferring reliable site characterization of the study region in the context of resonant frequencies and site amplification behavior. Apart from this, influence of local lithology is also explored with a view to correlate with the computed frequencies. Besides, an empirical relationship between fundamental frequencies and sedimentary thickness pertinent to this region is developed. Similarly, the sub-surface shear wave velocity is empirically related to the depth of the overburden thickness. So far the estimations regarding the $\mathrm{H} / \mathrm{V}$ peak frequencies are concerned; two categories of site frequencies are contemplated. The higher side of fundamental frequencies observed in majority of the sites could be correlated with the compact form of strata. It could also be attributed to the thinning of sedimentary structures beneath the sites as observed in many of studies e.g., Lombardo et al., ${ }^{12,50}$ The sites revealing lower frequencies can be interpreted to be characterized by overburden thickness. The overall estimate of fundamental frequencies in the form of contour refers to Figure 6 indicate a wide variation. Some sites (e.g Laban, Rinsa Colony) [Lat-25.57 to $25.59^{0}$; Long- $91.87^{\circ}$ to $91.89^{\circ}$ ] situated in the central part of Shillong City yield lower estimates of fundamental frequencies in the range of 1 to $2 \mathrm{~Hz}$. This observation matches well with the local site condition. However, certain sites (e.g, Pynthorumkhrah, Lumparing etc.) in Shillong City reveal higher estimates of resonance frequencies.

These observations are established to be in good agreement with the local geologies, as evidenced in the geological map which reveal the fact that the sites showing higher estimates of resonant frequencies are underlain by different form of rock strata such as sandstones, quartzites and conglomerates etc Figure 12. In order to better understand the spatial variation of fundamental frequencies in Shillong City, the subsurface geology along two profiles $\mathrm{AB}$ and $\mathrm{CD}$ pertaining to the availability of borehole information in conformity with the locations of the ambient noise sites are reconstructed. When correlated with the variation of the fundamental frequencies, the site geology is found to tally with the estimated peak frequencies through $\mathrm{H} / \mathrm{V}$ ratio. Carried out such type of correlation studies wherein the variability in $\mathrm{H} / \mathrm{V}$ peak frequencies was interpreted in terms of the existing lithology. In both the two observed profiles $\mathrm{AB}$ and $\mathrm{CD}$, the reconstructed sections drawn by virtue of the borehole-log information indicate a heterogeneous formation of structures. In fact, it is well represented by the corresponding fundamental frequencies observed in these two profiles which also show a wide variability in response to the underlying formations characteristic of the reconstructed cross section. Along the $\mathrm{AB}$ profile, lower frequencies cover lower amplitudes whereas higher frequencies correspond to higher amplitudes. Souriau et al., ${ }^{51}$ observed deamplification at frequencies greater than $3 \mathrm{~Hz}$. The variation of amplitude as found in the $\mathrm{CD}$ profile reveals a similar trend which can be interpreted to be caused by topographic effects. ${ }^{52}$ Through Numerical simulation of input acceleration histories aided by geotechnical inputs in the form of lithologs and N-values from Standard Penetration Test, it is sought to analyze site-specific non linear soil behavior. This necessitates the incorporation of shear wave velocities which are actually deduced by the widely used empirical relationships (Ohta and Gotto, 1978; Immai
\& Tonochi, 1982) exploiting the N-values. Here also, the estimates of the ground motion parameters particularly the peak ground acceleration shows an anomalous behavior pertaining to the borehole sites. $^{53-61}$

\section{Conclusion}

In this study, we endeavor to map the distribution of fundamental frequency obtained from recorded ambient noise with $\mathrm{H} / \mathrm{V}$ ratio. In spite of some limitations of $\mathrm{H} / \mathrm{V}$ method, we obtain some notable features. Most importantly it is observed that fundamental resonance frequency for Shillong city ranges between 3 to $8 \mathrm{~Hz}$. In fact most parts of the area are characterized by higher fundamental frequency which may be correlated with the existing thicker strata of basement rocks underlying the surface layer yielding sharp peaks in the $\mathrm{H} / \mathrm{V}$ ratio. At short distances, wide variation of resonance frequencies in the $\mathrm{H} / \mathrm{V}$ ratio is observed. This may be viewed as an indication of lateral heterogeneity prevailing in soil layers of the region. Moreover, a good correlation is found to exist between resonance frequency estimates and existing lithology. This is well supplemented by the relevant borehole information at some of the selected sites. Additionally, the results, that we obtain from numerical analysis carried out through non-linear site response analysis with the input of acceleration histories from a nearby earthquake from the study area, bear a substantial resemblance with $\mathrm{H} / \mathrm{V}$ ratio results so far the resonant frequency estimates are concerned. Within the limitations of H/V ratio (Ghasemi et al. 2009), one can reliably infer the fundamental frequency of a site in a rapid manner provided there exists an impedance contrast between the surface layer and the layer beneath. Besides, the $\mathrm{H} / \mathrm{V}$ ratio technique is able to furnish specially the superficial site conditions; hence, in our case too, we believe that the results yielded by the ambient noise measurements and the following $\mathrm{H} / \mathrm{V}$ assessments might incorporate the site conditions superficially; not the conditions in depth. On the basis of these observations delimited by certain restraints, we believe that the present work will help as an initial building block towards detailed microzonation study in Shillong City aided by more analysis such as MASW, GPR etc.

\section{Acknowledgments}

We express our sincere gratitude to Dr. P.G Rao, Director, NEISTJorhat for his constant encouragement and permission to publish the work. We are also grateful to Mo.E.S [Project No. DST/23(533)/ SU/2005], Delhi for their financial support. The Civil Engineering Department of IIT, Guwahati is also acknowledged for providing necessary data.

\section{Conflicts of interest}

The author declares there is no conflict of interest.

\section{References}

1. Oldham RD. Report on the great earthquake of $12^{\text {th }}$ June $1897 \mathrm{Mem}$. Geol Surv India. 1899;29:1-379.

2. Poddar MC. Preliminary report of the Assam earthquake of $15^{\text {th }}$ August 1950. Geol Surv India Bull Ser. 1950;2:1-40.

3. Tillotson E. The Great Assam earthquake of 1950, the completion of papers on the Assam Earthquake of August 15, 1950, compiled by MB Ramachandra Rao. 1953;94-96.

4. BMTPC. Vunerability atlas-2 ${ }^{\text {nd }}$ edition peer group $M o H \&$ UPA; seismic zones of India IS, 1983-2002. 2003. 
5. Evans P. The Tectonic Framework of Assam. J Geol Soc India 5. $1964 ; 80-96$.

6. Nandy DR. Geodynamics of Northeastern India and the adjoining region. ACB publications, Calcutta. 2001. p. 209.

7. Badrane S, Bahi L, Jabour N. Site effects in the city of Rabat (Morocco) J Geophys Eng. 2006;3.

8. Fernandez LM, Brandt MBC. The reference spectral noise ratio method to evaluate the seismic response of a site. Soil Dyn Earthquake Eng. 2001;20:381-388.

9. Cara F, Cultera G, Azzara RM, et al. Microtremor measurements in the city of Palermo, Italy, Analysis of the correlation between local Geology and damage. Bull Seismo Soc Am. 2008;98:1354-1372.

10. Bonnefoy-Claudet S, Leyton F, Baize S, et al. Potentiality of microtremor to evaluate site effects at shallow depths in the deep basin of Santiago de Chile. Proc $14^{\text {th }}$ World Conference on Earthquake Engineering. 2008. p. $1-8$.

11. Mundepi AK, Lindholm C, Kamal. Soft soil mapping using horizonta to vertical ratio (HVSR) for Seismic Hazard Assessment of Chandigarh City in Himalayan Foothills, North India. Jour Geol Soc India. 2009;74(5):551-558

12. Lombardo G, Rigano R. Local seismic response in Catania (Italy), A test area in the Northern part of the Town. Eng Geo. 2007;94(1-2):38-49.

13. Biswas R, S Baruah. Site Response Estimation by Nakamura Method: Shillong City, Northeast India. Memoir of the geological society of India, No. 77, ISBN: 978-81-907636-2-2, 2001. p. 173-183.

14. Bard PY. Microtremor measurements, a tool for site affects estimation? Proc $2^{\text {nd }}$ International Symposium Effect of Surface Geology on Seismic Motion. 1999;1251-1279.

15. Biswas R, D Bora, S Baruah. The Effects of Attenuation and Site on the Spectra of Microearthquakes in the Shillong Region of Northeast India. Pure and Applied Geophysics. 2013a;170(11)1833-1848.

16. Biswas R, D Bora, S Baruah. Influence of attenuation and site on microearthquakes' spectra in Shillong region, of Northeast. India: A case study. Acta Geophysica. 2013b;61(4):886-904.

17. Biswas R, D Bora, S Baruah. Mapping Sediment Thickness in Shillong City of Northeast India through Empirical Relationship. Journal of Earthquakes. 2015; Article ID 572619.

18. Biswas R, S Baruah, S Baruah. A Brief overview of site response estimation techniques. Mistral Services: Italy, 2014;ISBN: 978-8898161-25-6.

19. Biswas R, S Baruah. Shear wave velocity estimates through combined use of two passive techniques of a tectonically active area. Acta Geophysica. 2016;64(6):2051-2076.

20. Biswas R. Non-Linear Earthquake Site Response Analysis: A case study in Shillong City. IJEHRM. 2016;3(4):1-2.

21. Komatitsch D, Vilotte JP. The spectral-element method, an efficient tool to simulate the seismic response of $2 \mathrm{D}$ and $3 \mathrm{D}$ geological structures. Bull Seismo Soc Am. 1998;88(2):368-392.

22. Ouchi T, Lin A, Maruyama T. The 1999 Chi-Chi (Taiwan) earthquake, earthquake fault and strong motions. Bull Seismol Soc Am. 2001;91:966976.

23. Hasancebi N, Ulusay R. Evaluation of site amplification and site period using different methods for an earthquake-prone settlement in Western Turkey. Eng Geol. 2006;87:85-104.

24. Duval AM, Vidal S, Meneroud P, et al. Caracas, Venezuela, Site effect determination with micro tremors. Pure Appl Geophys. 2001;158(12):2513-2523
25. Lebrun B, Hatzfeld D, Bard PY. A site effect study in urban area experimental results in Grenoble (France). Pure Appl Geophys. $2001 ; 158(12): 2543-2557$.

26. Panou A, Theodulidis N, Hatzidimitriou P, et al. Reliability of ambient noise horizontal to vertical spectral ratio in urban environments, the case of Thessaloniki City (Northern Greece). Geophys. 2005;162:891-912.

27. Gueguen P, Chatelain JL, Gullier B, et al. An indication of the soil topmost layer response in Quito (Ecuador) using noise $\mathrm{H} / \mathrm{V}$ spectral ratio. Soil Dyn Earthquake Eng. 2000;19:127-133.

28. Garcia-Jerez A, Navarro M, Alcala FJ. Shallow velocity structure using joint inversion of array and $\mathrm{h} / \mathrm{v}$ Spectral ratio of ambient noise, The case of Mula Town (SE of Spain). Soil Dyn and Earthquake Eng. 2007;27:907-919.

29. Duke CM, Johnsen KE, Larson L. Effects on site lassification and distance on instrumental indices in the San Fernando earthquake. 20007. $50 \mathrm{p}$

30. Mikhailova NN, Aptikaev FF. Some correlation relations between parameters of seismic motions. J Earth Prediction Res. 1996;5:257267.

31. Nakamura Y. A method for dynamic characteristics estimation of Sub surface using microtremor on the surface. Railway Technical Research Institute Report. 1989;30(1):3025-3033.

32. Rao JM, Rao PGVS. Geology, Geochemistry and Palaeomagnetic study of Cretaceous Mafic Dykes of Shillong Plateau and Their Evolutionary History Indian Dykes, Geochemistry. Geophysics and Geomorphology. 2008;589-607.

33. Chattopadhaya N, Hashimi S. The Sung valley alkaline ultramaffic carbonatite complex, East Khasi Hills district, Meghalaya. Rec Geo Surv India. 1984;113:24-33.

34. Sar SN. An interim report on ground water exploration in the Greater Shillong area, Khasi Hills District, Meghalaya, Memo report, Central Ground Water Board. 1973.

35. Kalita BC. Ground water prospects of Shillong Urban Aglomerate. Unpublished report. CGWB. 1998

36. Rao JM, Rao GVSP. Precambrian mafic magmatism of Shillong plateau, Meghalaya and their evolutionary history. $J$ Geol Soc India. 2009;73:143-152

37. Bidyananda M, Deomurari MP. Geochronological constraints on the evolution of Meghalaya massif, northeastern India, An ion microprobe study. Curr Sci. 2003;93(11):1620-1623.

38. Srinivassan P, Sen S, Bandopadhaya PC. Study of variation of Paleocene-Eocene sediments in the shield areas of Shillong Plateau. Rec Geol Surv India. 1996;129:77-78.

39. Bilham R. England P. Plateau pop-up in the Great 1897 Assam earthquake. Nature. 2001;410(6830):806-809.

40. Gupta HK, Singh VP. Teleseismic P-wave residual Investigations at Shillong, India. Tectonophysics. 1980;66(4):19-27.

41. Khatri KN, Chander R, Mukhopadhyay S. A model of active tectonics in the Shillong Massif region, Himalayan Orogen and Global Tectonics. 1992.

42. Konno K, Ohmachi T. Ground motion characteristics estimated from spectral ratio between horizontal and vertical components of microtremor. Bull Seismol Soc Am. 1998;88:228-241.

43. Huang CS, Yeh $\mathrm{CH}$. Some properties of the Randomdec signatures Mechanical Systems and Signal Processing. 1993;13:491-507.

44. Haghshenas E. Condition geotechnique et alea sismique local a Teheran. PhD Thesis, Joseph Fourier University, Grenoble (France). 2005. p. 288. 
45. Field E, Jacob K. The theoretical response of sedimentary layers to ambient seismic noise. Geophys Res Lett. 1993;20(24):2925-2928.

46. Tokeshi JC, Sugimura Y. On the estimation of the natural period of the round using simulated microtremors. In, $2^{\text {nd }}$ International Symposium on the Effects of Surface Geology on Seismic Motion, Yokohama, Japan. 1998;2:651-664.

47. Lermo J, Chavez-Garcia FJ. Are microtremors useful in site response evaluation? Bull Seismol Soc Am. 1994;84:1350-1364.

48. Bardet JP, Bobita T. Nonlinear Earthquake Site Response Analysis University of Southern California. Department of Civil Engineering. 2001.

49. SESAME, 2004. Guidelines for the implementation of the $H / V$ spectral ratio technique on ambient vibrations measurements, processing and interpretation. SESAME European research project WP12-Deliverable D23.12, December

50. Guillier B, Chatelain J, Claudet SB, et al. Use of ambient noise, From Spectral amplitude variability to H/V Stability. J Earth Eng. 2004;11(6):925-942.

51. Souriau A, Roulle A, Ponsolles C. Site Effects in the City of Lourdes, France, from $\mathrm{H} / \mathrm{V}$ Measurements: Implications for Seismic-Risk Evaluation. Bull Seism Soc Am. 2007;97(6):2118-2136.

52. Dubos N, Souriau A, Ponsolles C, et al. Etude des effets de site dans la ville de Lourdes (Pyrénées, France) par la méthode des rapports spectraux. Bull Soc Géol Fr. 2003;174(1):33-44.

53. Baruah S, Hazarika D. A GIS based tectonic map of Northeastern India Curr Sci. 2008;95:176-177.
54. Bonnefoy-Claudet S, Cotton F, Bard PY. The nature of the seismic noise wave field and its implication for site effects studies, a literature review. Earth Sci Rev. 2006;79:205-227.

55. Cara F, Giulio G, Roveli A. A study on Seismic Noise Variations at Colfiorito, central Italy, Implications for the Use of H/V Spectral Ratios. Geophys Res Lett. 2003;30.

56. Dunand F, Bard PY, Chatelain JL. Damping and frequency from Randomdec method applied to the in situ measurements of ambient vibrations, evidence for effective soil structure interaction. Proceedings of 12th European conference on earthquake engineering. London. 2002.

57. Ghasemi H, Zare M, Fukushima Y, et al. Applying empirical methods in site classification, using response spectral ratio (H/V), A case study on Iranian Strong motion network (ISMN). Soil Dyn Earthquake Eng. 2009;29(1):121-132.

58. Imai $\mathrm{T}$, Tonouchi $\mathrm{K}$. Correlation of $\mathrm{N}$-value with $\mathrm{S}$-wave velocity and Shear Modulus. In, Proceedings 2nd European Symposium on Penetration Testing Amsterdam. 1982;57-72.

59. Richter CF. Elementary Seismology. WH Freeman et al., editors. 1958. p. 768.

60. Theodulidis N, Bard PY, Archuleta R, et al. Horizontal to Vertical Spectral ratio and geological Conditions, The case of Garner valley downhole array in southern California. Bull Seism Soc Am. 1996;86(2):306-319.

61. Wakamatsu K, Yasui Y. Possibility of estimation for amplification characteristics of soil deposits based on ratio of horizontal to vertical spectra of microtremors. In, 11th World Conference on Earthquake Engineering, Acapulco, Mexico. 1996. 